Railway Engineering

Jan. 2021

Issue:13, Page: 106-114

Research Article

doi: 10.47072/demiryolu. 831702

http://dergipark.org.tr/demiryolu

e-ISSN: 2687-2463, ISSN: 2149-1607

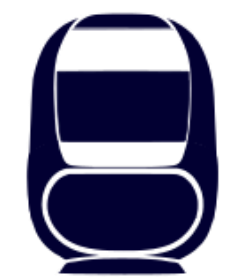

\title{
Nehir Akımlarının Derin Öğrenme ile Tahmini ve Akımların Demiryolları Güzergâhına Etkisi
}

\author{
Hüseyin Çağan KILINÇ® \\ İstanbul Esenyurt Üniversitesi, Mühendislik-Mimarlık Fakültesi, İņ̧aat Mühendisliği \\ Bölümü, İstanbul, Türkiye
}

huseyincagankilinc@esenyurt.edu.tr

(Alınış/Received: 26.11.2020, Kabul/Accepted: 15.12.2020, Yayımlama/Published: 31.01.2021)

\begin{abstract}
Öz: Son yıllarda meydana gelen aşırı yağış, taşkınlar ve dere yataklarının öngörülmeyen bir şekilde taşması demiryolu kazalarını oluşturan önemli etkenlerden biri haline gelmiştir. Bu durum su kaynaklarını doğru yönetmenin önemini ortaya koymaktadır. Havzaların morfolojik özelliklerinin belirlenmesi ve su kaynaklarının sürdürülebilir olması için periyodik nehir akım ölçümlerinin yapılması gerekmektedir. Anlık yapılan ölçümler çok zaman aldığından, pratik ölçüm yöntemleriyle nehir akımları tahmin edilmektedir. Ancak her akım gözlem istasyonu (AGİ) için bir debi-seviye bağıntısı belirlenmesi ve debi-seviye bağıntılarının zamanla değişebilmesinden dolayı debi tahminlerinde hatalar görülebilmektedir. Bunun için farklı tahmin yöntemlerine gereksinim duyulmaktadır. Bu çalışmada Göksu Nehri üzerindeki D21A183 No'lu Aşağıçöplü köyü, Akdere AGI' den elde edilen günlük akım verileri üzerinde, Derin Öğrenme Modeli oluşturularak, modelin performansı analiz edilmiştir. Modelin performansını analiz ederken gerçek değerler ve tahmin edilen değerler arasındaki yakınlık incelenmiștir. Bu akım değerleri 3 ve 4 zaman (günlük) ötelemeli senaryolara ayrılıp 2 ayrı veri setine dönüştürülmüştür. Gerçeğe en yakın değerler en büyük $\mathrm{R}^{2}$ değerine sahip 4 ötelemeli senaryoya ait sonuçlardır. Sadece akım değerleri kullanılarak tahminde bulunulmuş ve başarılı sonuçlar elde edilmiştir. Yağış, sıcaklık gibi girdi parametreleri eklenerek daha farklı senaryolar oluşturulması, gelecek çalışmalar için faydalı olacaktır. Ayrıca tahmin edilen bu akım değerlerinin Göksu nehri yakınlarına kurulması düşünülen potansiyel bir demiryolu hattının projelendirilmesinde yardımcı olacağı düşünülmektedir.
\end{abstract}

Anahtar kelimeler: Derin Öğrenme, Akım, Demiryolları

\section{Prediction of River Flows using Deep Learning and the Effect of Flows on Railways Routes}

Abstract: In recent years, one of the most important causes of railway accidents is excessive rainfall, floods, and the overflow of unpredictable stream beds flooding. This shows displays the significance of proper management of water resources. Periodic river flow measurements are required in order to determine the morphological aspects of the basins and sustainability of water resources. River flows are measured by practical measurements; as instant measurements are time-consuming. Therefore, a flow-level correlation must be determined for each flow measurement station. However, misestimation can be observed as a result of the fact that flow-level correlations can differ over time. It reveals the demand for other estimation methods. In this study, a Deep Learning Model has been created with the use the daily flow measurement data by Akdere FMS of Aşağıçöplü with the number of D21 A183 and its performance has been analyzed. Additionally, the performance of the model was analyzed by creating a Deep Learning Model. During this process, the proximity between actual and predicted values were examined. These flow values were separated into 3 and 4 days of delayed scenarios and turned into two data sets. The 4-day delayed scenario which has the highest $\mathrm{R}^{2}$ was the most proximate value to the actual value. Accurate results were received

Atıf için/Cite as: H.Ç. Kılınç, "Nehir akımlarının derin öğrenme ile tahmini ve akımların demiryolları güzergâhına etkisi," Demiryolu Mühendisliği, no. 13, pp. 106-114, Jan. 2021. doi: 10.47072/demiryolu.831702 
by only using flow values through estimating. It will be beneficial to create different scenarios for future studies by adding parameters such as precipitation and temperature. As a result, it is assumed that the obtained results may provide useful information for a railway project which can be constructed near to the Göksu River.

Keywords: Deep Learning, Stream Flow, Railways

\section{Giriș}

Yeryüzünde canlıların yaşaması için suyu kullanmak ve kontrol altına almak gerektiğinden insanlar tarihin başlangıcından beri su ile ilgilenmişler, suyun özelliklerini tanımaya, hareketini yöneten kanunları belirlemeye, oluşturabileceği tehlikeleri önlemeye ve sudan en iyi şekilde yararlanmaya çalışmışlardır. İnsan yaşamının her döneminde gerekli olan suyun varlığı ve kalitesi oldukça önemlidir. Son yıllarda meydana gelen demiryolu hasarlarının nedenlerinden biri olan dere yataklarının taşması, suyun doğru yönetiminin önemini daha da arttırmıştır [1].

Demiryolu güzergâhlarına yaklaşık veya paralel olarak akan, tren yolu altından bir menfezle geçen bir yan derenin taşması gibi durumlar bu hasarların oluşmasında ciddi bir etken oluşturmaktadır. Ayrıca güzergâhı oluşturan bölgelerin hidrojeolojik özellikleri ve mühendislik parametrelerinin yeterince dikkate alınmaması, kontrol, izleme, bakım ve onarım süreçlerindeki ihmaller nedeniyle de bu hasarlar meydana gelmektedir. Demiryolu güzergâh çalışmalarında, jeolojik-jeoteknik çalışmalar göz önüne alınırken hidrojeolojik etütler önem arz etmektedir. Yeterli jeolojik-jeoteknik araştırmalar yapılmaması ilerleyen zamanlarda ortaya çıkan etmenlerden kaynaklı olarak ciddi sorunlara neden olmaktadır [1].

Çalışmada TCDD 5. Bölge Müdürlüğ̈̈ mıntıkasında yer alan demiryolu hatları ile aynı bölgede yer alan Göksu nehrinin dataları incelenmiş ve demiryolu güvenliği açısından sorun oluşturabilecek hidrolojik etkenlerden biri olan akım değerleri derin öğrenme yöntemi ile tahmin edilmeye çalışılmıştır. Su kaynaklarının tahmin edilmesi ve yönetilmesi, dünya üzerinde bulunan sınırlı tatlı su kaynakları nedeniyle gerçekten önemlidir [2].

Su Kaynakları yönetimi, nehir havzası yönetimi ve su kaynakları planlaması arasındaki yakın ilişki olarak tanımlanabilir [3]. Nehir yönetimi için hayati öncelik, havza yönetimidir. Ekolojik rejim ve arazi toprağının fiili olarak değerlendirilmesi su yönetimi için vazgeçilmez bir gereksinimdir. Havza yönetimi mevcut kaynakları planlama ve korumaya yönelik olmalıdır. ' 'Entegre Havza Yönetimi' son zamanlarda suyu verimli kullanmak adına tüm Dünyada olduğu gibi Türkiye'de de önem kazanmıştır [4].

Havzaların morfolojik özelliklerinin belirlenmesi su kaynaklarının sürdürülebilir olarak, havza bazında bütüncül yönetim planlanması açısından mühendisler ve karar vericilere önemli yararlar sağlamaktadır. Bu amaçla, havzalar ile ilgili çalışmalarda bilgisayar hidrolojik modellemelerin sayıları ve kullanım alanları oldukça artmıştır. Su kaynakları potansiyelinin belirlenmesinde, taşkın veya kuraklık durumlarında baraj haznelerinin davranışlarının kestirilmesinde ve buna bağlı gelecek dönem senaryolarının oluşturulmasında büyük önem taşıyan akım tahmin modelleri hidrolojik model çalışmalarının temelini oluşturmaktadır [5].

Bu çalışmanın amacı aşıı yağış, taşkın ve sellenmelerden kaynaklı dere yataklarının taşması sonucu demiryolları güzergâhlarında meydana gelebilecek hasarların ve oluşması muhtemel kazaların önüne geçebilmek için doğru akım tahminlerinin oluşturularak gerekli önlemlerin alınmasına fayda sağlamaktır. Bu bağlamda Göksu Nehri üzerindeki D21A183 No'lu Aşağıçöplü köyü Akdere AGI'den elde edilen akım verileri üzerinde Derin öğrenme modeli oluşturularak 
modelin performansı gerçek ve tahmin edilen değerler arasındaki yakınlık incelenerek analiz edilmiştir.

Kızılaslan vd. [6], Sakarya Nehri'nin akım miktarını ileri beslemeli geriye yayılımlı yapay sinir ağları ve çeşitli senaryolar altında en iyi tahmine ulaşmak için modellemişlerdir. Küçükerdem vd. [7], Sandıklı Kestel Barajı'na ait 1986-2008 yılı verileri ile uyarlamalı ăg tabanlı bulanık çıkarım sistemi (ANFIS) modelini kullanarak aylık hacimlerin tahminini yapmaya çalışmışlardır ve sonuç olarak uygun küme sayılarına göre yapılan modellerin rastgele oluşturulan modellere göre daha düşük hata yüzdesine sahip sonuçlar verdiğini belirtmişlerdir. Terzi ve Özcanoğlu [8], Göksu Nehri'nin akım tahminini genetik programlama ile modellemişlerdir. Modellemede seçilen istasyonun akım verileri ve havzadaki diğer istasyonların akım verilerinden faydalanmışlardır. Sonuç olarak gen ifade programlama yönteminin günlük akım tahmininde başarılı sonuçlar verdiğini belirtmişlerdir. Kökçam vd. [9], Meriç Nehri üzerindeki İpsala, Plovdiv, Svilengrad ve Kirişhane akım gözlem istasyonlarındaki 2005-2011 yılları arasındaki akım ölçüm verilerini kullanarak bir yapay sinir ağı modellemişlerdir. Model ile elde edilen tahminler çeşitli performans metotları yardımıyla gerçek değerlerle karşılaştırılmış Yapay sinir ağlarının nehir akımlarının tahmini konusunda başarılı sonuçlar verdiğini görmüşlerdir. Demirpençe [10], Köprüçay akım gözlem istasyonundan elde edilen günlük akım değerlerinin çeşitli kombinasyonlarını girdi olarak kullanarak, 6 model oluşturmuştur. İleri beslemeli geriye yayılımlı yapay sinir ağları metodu ile tahmin edilen Köprüçay akımları, lineer regresyon (LR) modeli sonuçlarıyla karşılaştırılmış ve daha iyi sonuçlar verdiğini gözlemlemiştir. Okkan ve Mollamahmutoğlu [11], Gediz havzasında yer alan Yiğitler Çayına ait günlük akımları yapay sinir ağları ile modellemişlerdir. Hazırlanan yapay sinir ağları (YSA) modeli çoklu doğrusal regresyon modeli ile karşılaştırılmış, model performansları, Yiğitler Çayına ait ölçülmüş günlük akım değerleri ile sınanmıştır. Analiz sonucu, yapay sinir ağı algoritması performansı regresyon modeline göre daha başarılı bulunmuştur. Terzi ve Köse [12], Göksu Nehri'nde bulunan Karahacılı (1714), Kırkkavak (1719) ve Hamam (1720) AGi'lerden alınan 1990-2010 yılları arasında günlük akım değerlerini kullanarak YSA modelleri geliştirmişlerdir. Geliştirilen modellerin performansları değerlendirilirken, belirginlik katsayısı ve ortalama mutlak hata değerleri kullanılmıştır. Modellerin performansları değerlendirildiğinde, YSA metodunun akım tahmininde kullanılabilir olduğunu gözlemlemişlerdir. Gemici vd. [13], Kızılırmak nehrinin yan kollarındaki 5 farklı istasyonun, 22 farklı akım koşullarında, akarsu en kesitini dilimlere bölmüş ve geometrisini çıkararak hız-alan yöntemiyle debisini belirlemişlerdir. Ölçülen değerlerle modellerin tahminleri arasındaki hataları belirlemişler ve model performanslarını kendi arasında karşılaştırmışlardır. En iyi performansın ANFIS modelinden elde edildiğini, debi tahmininde ise seviye ölçümlerinin tek başına yeterli sonuç vermediğini, diğer giriş verileriyle beraber ise en etkin giriş parametresi olduğunu belirlemişlerdir. Yurdusev vd. [14], Kapalı bir havza üzerinde yapay sinir ağları ile akım ve yağış tahminlerinde bulunmuşlar ve aylık akımların bu model ile iyi sonuçlar verdiği sonucuna ulaşmışlardır. Gümüş vd. [15], Orta Fırat Havzasındaki 2157 numaralı AGI'nin aylık akımları ile 17204 numaralı yağış gözlem istasyonunun aylık yağış verilerinin ilişkisini incelemişlerdir. İnceleme yapılırken Çoklu Doğrusal Regresyon (ÇDR) yöntemi ile Yapay Sinir Ağları Yöntemlerini karşılaştırmışlardır. Çalışma sonunda YSA metotlarının ÇDR metoduna göre daha başarılı sonuç verdiği gözlemlenmiştir. Okkan ve Dalkılıç [16], Kemer Baraj Havzası'na ait aylık akımlara göre bir Radyal Tabanlı Yapay Sinir Ağı modeli (RTYSA) geliştirmişlerdir. Gözlem sonuçları ile modelden çıkan sonuçlar uzun dönem ve mevsimsel olarak karşılaştırıldığında; geliştirilen modelin, bir baraj havzasının aylık akımlarının tahmininde başarıyla kullanılabileceğini göstermişlerdir. Yağış-akış modeli, taşkın modeli gibi hidrolojik modeller, teknolojideki son gelişmelerden dolayı gerçekçi çözümler sunar. Bunlar çok faydalıdır, ancak gerçekte çoğunun birçok parametresi vardır ve bu parametreler iyi bir simülasyon için ayarlanmalıdır [17]. Herhangi bir verinin kademeli olarak kullanılabilir olması ve bilgisayar (yazılım) gücünün artmasıyla, son 
hidrolojik analizlerin çoğu, doğru çözümler geliştirmek için temel metodolojik yaklaşım olarak yapay sinir ağları, genetik algoritma ve derin öğrenme gibi modellerden yararlanmaktadır [18]. Akarsulardaki akımı eldeki veriler ile tahmin etmek su kaynaklarındaki planlama ve işletim için önem arz etmektedir [19].

\section{Materyal ve Metot}

\subsection{Materyal}

Çalışma alanı Türkiye'nin $37^{\circ} 54^{\prime}$ kuzey enlemleri ile $37^{\circ} 59^{\prime}$ doğu boylamları arasında yer alan Göksu Nehri havzasıdır. Göksu Nehri, Kahramanmaraş ilinin Nurhak ilçesi yakınlarında doğmakta ve Gölbaşı Adıyaman yakınındaki Fırat Nehri'ne karışmaktadır. Bu alan Nurhak (3090 m) Dağlarından başlayıp Adıyaman boyunca Koç Dağı $(2562 \mathrm{~m})$ eteklerine kadar uzanır. Nehrin toplam uzunluğu $118 \mathrm{~km}$, debisi ise $63 \mathrm{~m}^{3} / \mathrm{s}$ 'dir [20]. Nehrin drenaj alanı Firat nehrinin batısıdır ve bu alan yaklaşı $648 \mathrm{~km}^{2}$ 'dir. Şekil 1'de Türkiye Cumhuriyeti Devlet Demiryolları (TCDD) 5. Bölge Müdürlügü mıntıkasına yakın bir lokasyonda bulunan ve kullanılan akımların alındığ GÖLBAŞI-ADIYAMAN yolunun 21. km'sinde bulunan Aşağıçöplü köyü Akdere Akım Gözlem İstasyonunun konumu verilmiştir [21]. Şekil 2'de TCDD'nin, 2019 y1l sonu itibariyle, Türkiye'nin 7 farklı bölgesine uzanan ve tüm bölgelere geçiş sağlayacak düzeyde olan demiryolu haritası gösterilmiştir [22]. Bölgedeki iklim Akdeniz iklimi olarak karakterize edilmiştir. Yıllık ortalama sıcaklık yaklaşık $15,2{ }^{\circ} \mathrm{Cdir} .36$ yıllık verilere göre, maksimum ortalama sıcaklık, Temmuz 2000 'de kaydedilen $27,9^{\circ} \mathrm{C}$ ve en düşük ortalama sicaklık ise Ocak $1965^{\prime}$ te kaydedilen $3,3^{\circ} \mathrm{C}$ 'dir. Yıllık ortalama yağış 551,6 mm olarak ölçülmüştür [23].

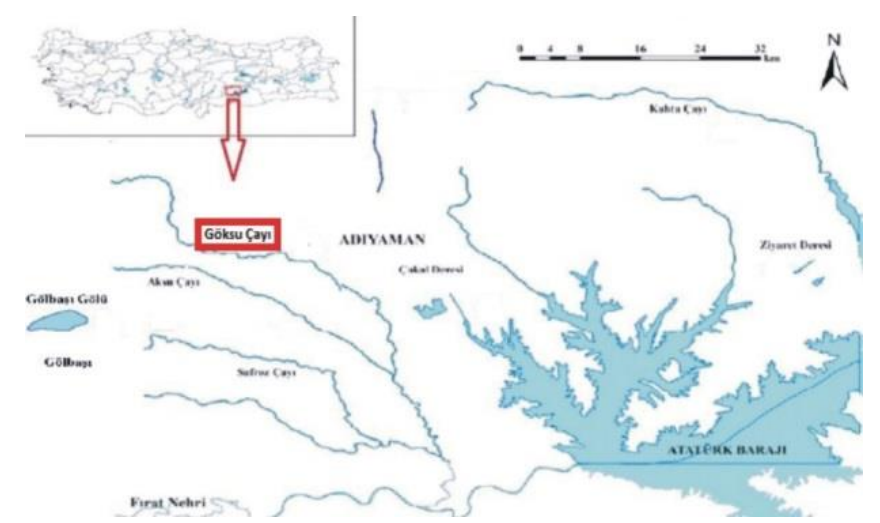

Şekil 1. Göksu Nehri ve Aşağıçöplü köyü akım gözlem istasyonu [21]

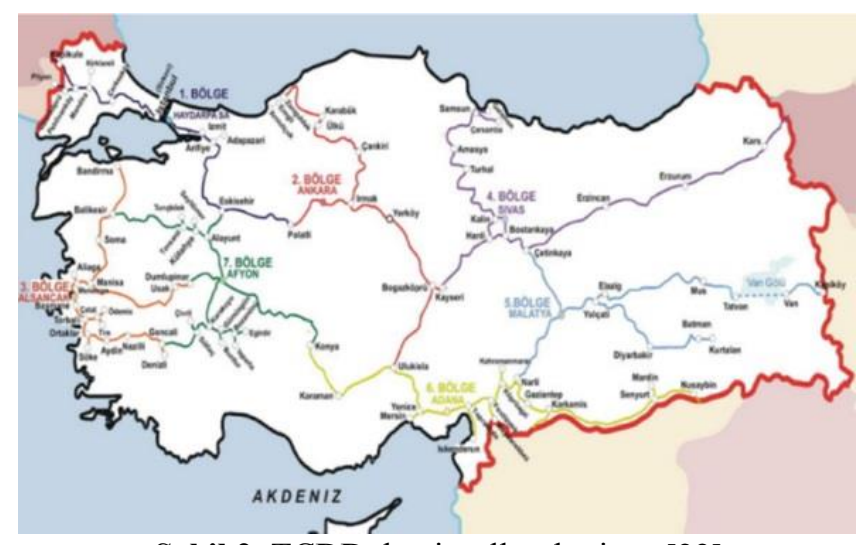

Şekil 2. TCDD demiryolları haritası [22] 
Çalışmada kullanılan veri seti, Türkiye'nin önemli nehirlerinden olan Göksu Nehri'nin D21A83

No'lu Aşağıçöplü köyü Akdere Akım Gözlem İstasyonundan elde edilen 2011-2018 yılları arasındaki akım değerleri örnek data olarak kullanılmışıtır. Tahmin sırasında iki ayrı zaman ötelemesi ile senaryolar geliştirilmiş ve üç ötelemeli ve dört ötelemeli olmak üzere iki ayrı veri seti elde edilmiştir. 3 ötelemeli veri seti 730; 4 ötelemeli veri seti ise 584 veriden oluşmaktadır. Hem 4 ötelemeli senaryoya ait verilerin hem de 3 ötelemeli senaryoya ait verilerin \%80'i eğitim için \%20'si ise test için kullanılmıştır.

\subsection{Metot}

Bir derin öğrenme kütüphanesi olan Keras Kütüphanesi kullanılarak, Sequential Modeli oluşturulmuştur. Çalışmada kullanılan model, 1 girdi katmanı, 4 gizli katman, 1 çıtı katmanından oluşmaktadır. Epoch (İterasyon) sayısı 4 ötelemeli senaryo için 1024, 3 ötelemeli senaryo için 2048 olarak belirtilmiştir. İyileştirici fonksiyonu 'Adam' kayıp fonksiyonu ise 'MAE' olarak tanımlanmıştır.4 zaman ötelemeli senaryoya ait veri seti için 5. Gün tahmininde 4 gün öncesinden başlayarak bir gün öncesine kadar olan günlük akım değerleri girdi olarak kullanılmıştır. 3 ötelemeli senaryoya ait veri setinde ise 3 gün öncesinden 1 gün öncesine kadar olan akım değerleri kullanılarak 4. Gün akım değerleri tahmin edilmiştir. Karşılaştırma yapılırken, korelasyon (R), determinasyon katsayısı $\left(\mathrm{R}^{2}\right)$, ortalama karesel hata $(\mathrm{OKH})$, ortalama mutlak hata $(\mathrm{OMH})$, kök ortalama karesel hata (KOKH), ortalama mutlak sapma (OMS), ortalama mutlak yüzdesel hata $(\mathrm{OMYH})$, standart sapma değerleri göz önünde bulundurulmuştur.

Derin öğrenme, makine öğreniminde, çoklu doğrusal olmayan dönüşümlerle verilerdeki üst düzey soyutlamaları modellemeye çalışan bir dizi algoritmadır. Beynin korteksindeki birçok nöron tabakasındaki aktiviteyi taklit etmektedir ve yapay sinir ağlarının (YSA) son teknoloji değerler dizisidir. Makine öğreniminde yeni bir atılımdır [24]. YSA tıpkı insan beyni gibi nöronlardan oluşur. Tüm nöronlar birbirine bağlıdır ve her bir girdi çıtıyı etkilemektedir. YSA 3 katmandan oluşmaktadır. Bunlar girdi, gizli ve çıktı katmanlarıdır. Derin Öğrenmedeki "Derin” ifadesi birden fazla gizli katman oluşturması anlamına gelmektedir. YSA'dan fark1 katman, katman insan ögrenmesini taklit ederek ve verilen veri kümesiyle veriye dayalı bir model oluşturarak kendi kendine öğrenme özelliklerine sahip olmasıdır. Derin öğrenmede, birden fazla özellik seviyesinin öğrenilmesine veya verilerin temsiline dayanan bir yapı vardır. Üst düzey özellikler, hiyerarşik bir temsil oluşturarak düşük düzey özelliklerden türetilir. Bu temsil, farklı soyutlama düzeylerine karşıllk gelen çoklu temsil düzeylerini öğrenir. Derin öğrenme temelde verinin temsilinden öğrenmeye dayanır [25].

\section{Bulgular ve Tartışma}

Tablo 1'deki performans değerlendirme kriterlerine göre en düşük KOKH, OKH, OMH, OMYH, STD, OMS değerlerinin ve en yüksek $\mathrm{R}, \mathrm{R}^{2}$ değerlerinin 4 ötelemeli senaryo verilerinden elde edildiği görülmüştür. Eğitim ve test sonuçları arasındaki yakınlığa bakıldığında ise modelle öğrenme verileri arasında oldukça yüksek bir ilişki olduğu görülmüş ve modelin veriyi iyi öğrendiği sonucuna varılmıştır. Tüm bu performans değerlendirme sonuçları dikkate alındığında 4 ötelemeli senaryonun ve derin öğrenme modelinin başarısının çok iyi olduğu gözlemlenmiştir. 
Tablo 1. Derin öğrenme modeli istatistiksel sonuçları

\begin{tabular}{|c|c|c|c|c|}
\hline \multirow{2}{*}{$\begin{array}{l}\text { Performans } \\
\text { Değerlendirme Yöntemi }\end{array}$} & \multicolumn{2}{|c|}{4 Ötelemeli Senaryo } & \multicolumn{2}{|c|}{3 Ötelemeli Senaryo } \\
\hline & Eğitim & Test & Eğitim & Test \\
\hline OMS & 0,1519 & 0,1507 & 0,1835 & 0,1864 \\
\hline $\mathrm{OKH}$ & 0,0473 & 0,0895 & 0,3215 & 0,4235 \\
\hline KOKH & 0,2174 & 0,2991 & 0,5670 & 0,6508 \\
\hline $\mathrm{OMH}$ & 0,2319 & 0,3440 & 0,4156 & 0,6185 \\
\hline OMYH & 23,1905 & 34,4004 & 41,5596 & 61,8464 \\
\hline STANDART SAPMA & 0,2202 & 0,6092 & 1,7063 & 2,9614 \\
\hline KORELASYON & 0,9925 & 0,9938 & 0,9808 & 0,9715 \\
\hline $\mathrm{R}^{2}$ & 0,9850 & 0,9887 & 0,9619 & 0,9438 \\
\hline
\end{tabular}

Gerçek değerlerle, tahmin edilen değerlerin karşılaştırıldığı en önemli grafiklerden olan regresyon grafiği 4 ötelemeli senaryo ve 3 ötelemeli senaryo için eğitim ve test sonuçlarına göre ayrı ayrı Şekil 2, Şekil 3, Şekil 4 ve Şekil 5 'te gösterilmiştir. Bu tip saçılma grafiklerinde gösterilen gerçek ve tahmin edilen değerler ne kadar doğrusalsa değerler birbirine o kadar yakındır. Şekillerdeki saçılma grafiklerine göre gerçeğe en yakın değerlerin bulunduğu sonuçlar en büyük $\mathrm{R}^{2}$ değerine sahip 4 ötelemeli senaryoya ait sonuçlardır. 4 ötelemeli senaryo için modelden çıkan eğitim ve test sonuçlarına ait $\mathrm{R}^{2}$ değerleri 0,9850 (Şekil 3) ve 0,9887 (Şekil 4) iken; 3 ötelemeli senaryo için $\mathrm{R}^{2}$ değerleri 0,9619 (Şekil 5) ve 0,9438 (Şekil 6) olarak belirtilmiștir. Şekil 7, Şekil 8, Şekil 9, Şekil 10' da gösterilen grafikler modelin çalıştırılmasında kullanılan 3 ve 4 ötelemeli senaryolara ait eğitim ve test sonuçları ile gerçek değerler arasındaki ilişkiyi göstermektedir. Tek çizgi gibi görünen yerlerde birebir sonuçlar yakalanmıştır. Dört ötelemeli senaryoya göre; eğitim veri setine ait gerçek değer 4,5000 ile tahmin değeri 2,7379 arasındaki farkın en fazla olduğu satır '463' (Şekil 7), test veri setine ait gerçek değer 0,5300 ile tahmin değeri 1,5659 arasındaki farkın en fazla olduğu satır '64' tür (Şekil 8).Üç ötelemeli senaryoya göre; eğitim veri setine ait gerçek değer 12,2000 ile tahmin değeri 5,0457 arasındaki farkın en fazla olduğu satır '378' (Şekil 9), test veri setine ait gerçek değer 5,2600 ile tahmin değeri 0,2760 arasındaki farkın en fazla olduğu satır '40' tır (Şekil 10). Bu noktalar aynı zamanda sapmaların da en fazla olduğu noktalardır. Sapma değerlerine bakıldığında dört ötelemeli senaryodaki sapma oranının üç ötelemeli senaryodaki sapma oranından daha düşük olduğu görülmektedir. Bu da dört ötelemeli senaryonun daha başarılı sonuçlar verdiğini göstermektedir.

Saçılma grafiklerine bakıldığında sonuçların oldukça başarılı olduğu anlaşılmaktadır. Modelden en iyi sonuçları elde edebilmek için model oluşturulurken farklı iyileştirici fonksiyonları, kayıp fonksiyonları ve iterasyon sayıları denenmiştir. Farklı sayılarda ve özelliklerde gizli katmanlar oluşturularak model birçok defa çalıştırılmıştır. Bu çalışmaların sonucunda üç ötelemeli ve dört ötelemeli senaryolardan elde edilen sonuçlar ayrı ayrı kıyaslanarak, alınan en iyi sonuçlara ait denemenin sonuçları çalışmada kullanılmıştır. Sonuçların gerçekçiliğini incelemek için ise bu bilgilerin kullanıldığı model tekrar tekrar çalıştırılmış ve her çalıştırmada birbirine benzer sonuçların elde edildiği gözlemlenmiştir. 


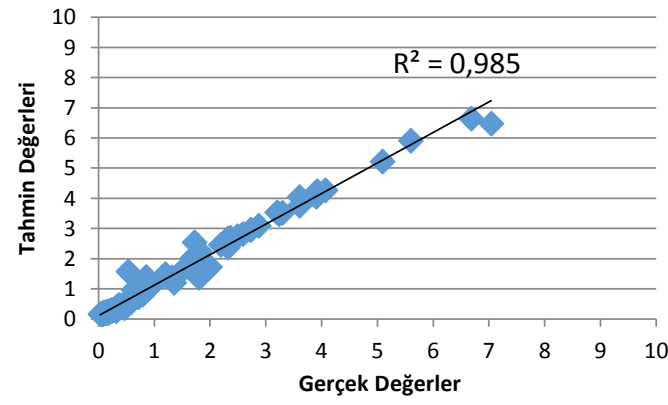

Şekil 3. Dört ötelemeli senaryoya göre test veri setine ait saçılma grafiği

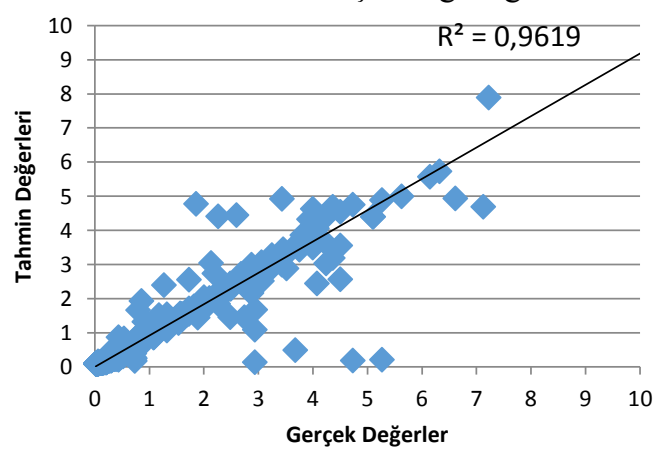

Şekil 5. Üç ötelemeli senaryoya göre eğitim veri setine ait saçılma grafiği

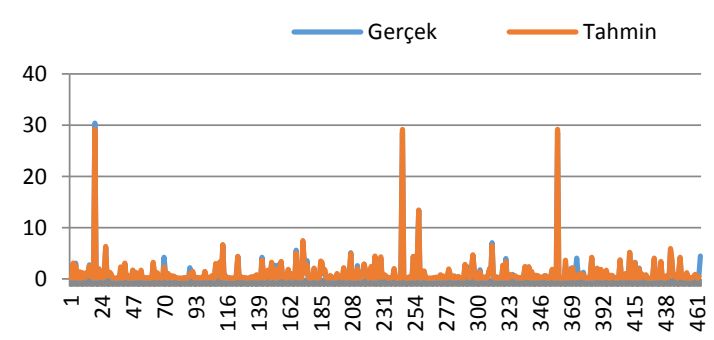

Şekil 7. Dört ötelemeli senaryoya göre eğitim Sonuçları

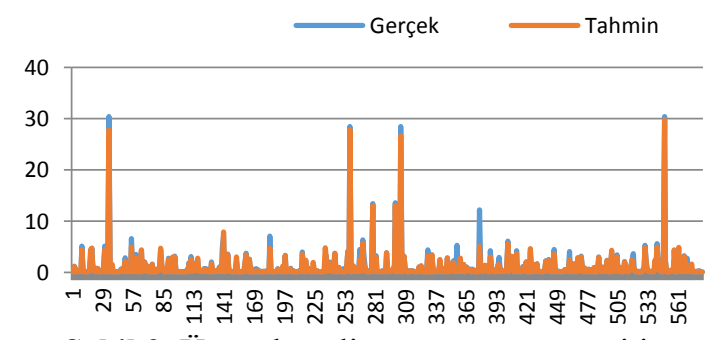

Şekil 9. Üç ötelemeli senaryoya göre eğitim sonuçları

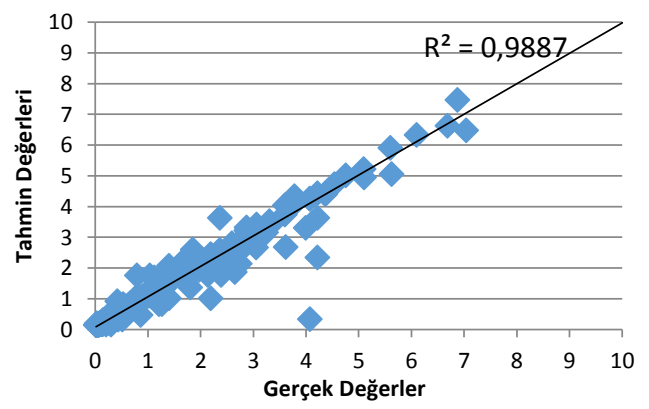

Şekil 4. Dört ötelemeli senaryoya göre eğitim veri setine ait saçılma grafiği

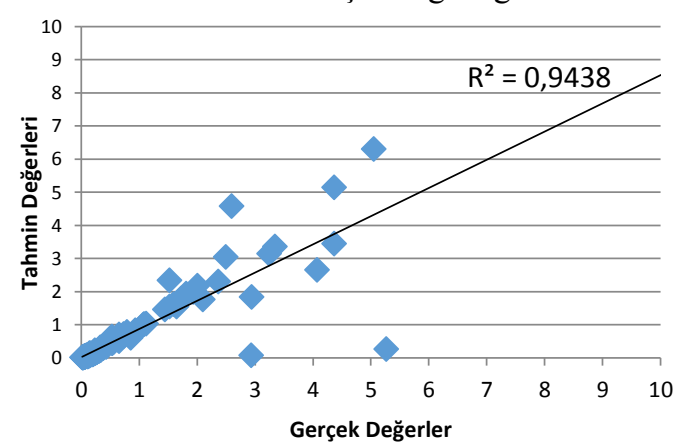

Şekil 6. Üç ötelemeli senaryoya göre test veri setine ait saçılma grafiği

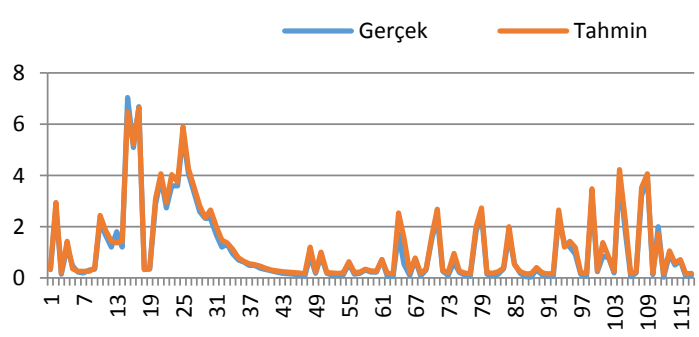

Şekil 8. Dört ötelemeli senaryoya göre test sonuçları

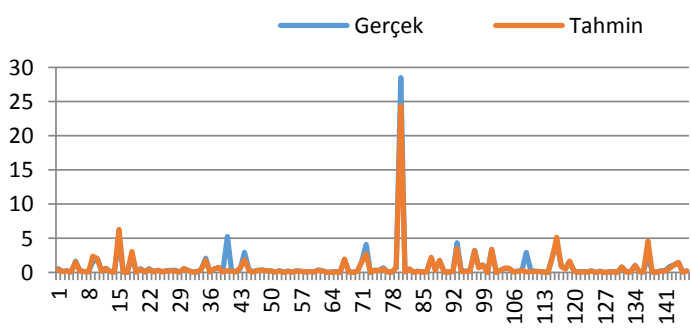

Şekil 10. Üç ötelemeli senaryoya göre test sonuçları

\section{Sonuç}

Akışlardaki düzenlemeleri ve uygulamaları planlarken güvenilir akış tahminlerinin kullanılması büyük önem taşımaktadır. Geleneksel akış tahmin yöntemleri, sistemin belirsizlikleri ve sistemin doğrusal olmayan özellikleri ile etkili tahminler yapmak için yetersiz olabilir. Bunun için alternatif tahmin yöntemleri gereklidir. Yapay sinir ağları, derin öğrenme gibi modellerin 
rastlantısal metotlara göre daha iyi ve gerçeğe yakın değerler verdiği gözlemlenmiş ve bu çalışmanın yapılması uygun görülmüştür. Demiryolu güzergâhlarında yol altındaki köprü ve menfez açıklıklarının taşkın debilerine uygun olarak yapılması önemlidir. Demiryolları güzergâhı boyunca inşa edilen yol dolguları, doğal drenaj için bir set oluşturarak taşkın riskini arttırmaktadır. $\mathrm{Bu}$ durum yağış havzasındaki morfolojik özelliklerin yanı sıra akarsuların taşkın anındaki sediment yükünün de dikkate alınmasını gerektirmektedir. Akım tahminlerinin kesinlik değerlerinin yüksek olması, taşkın ve sel kontrolleri, olası hasarların ve kazaların da önüne geçmekte fayda sağlayacaktır. Buna ek olarak, yüksek akış ne kadar çok olursa olsun, yol dolgu inşaatı, arkasında biriken suyun dolguyu ve hatta dolgu altındaki ince taneli yumuşak zemini aşındırmayacak şekilde inşa edilmelidir. Yalnızca akım değerlerinden elde edilen verinin öteleme yöntemi ile zenginleştirilmesi ve derin öğrenme modeli ile birlikte kullanılarak başarılı sonuçlar elde edilmesi; daha sonraki çalışmalarda akım değerlerinin tahmininde yol göstericidir. Ayrıca tahmin edilen bu akım değerleri ile Göksu nehri yakınlarına kurulması düşünülen potansiyel bir demiryolu hattının projelendirilmesi ve yapılabilirliği açısından önemli bir kaynak olacaktır.

\section{Kaynakça}

[1] A. İstanbulluoğlu, F. Konukçu, İ. Kocaman, 2006. 'Trakya Bölgesi su kaynaklarının geliştirilmesi ve sulu tarım uygulamaları: mevcut verilerin sorunların çözümü için analizi”, Tekirdă̆ Ziraat Fakültesi Dergisi, 3(2): 139-152.

[2] T. Küçükerdem, M. Kilit, K. Saplıoğlu 'Bulanık çıkarım sistemlerinde kullanılan küme sayılarının Kortalamalar ile belirlenmesi ve baraj hacmi modellenmesi: Kestel barajı örneği', Pamukkale Üniversitesi Mühendislik Bilimleri Dergisi, 25(8), 962-967, 2019.

[3] M. Teonian, "Su kaynakları yönetimi ve Türkiye", Jeoloji Mühendisliği Dergisi, 28(1), 27-38, 2004.

[4] H. Bach et al., "From local watershed management to integrated river basin management at national and trans boundary levels", Watershed Management Scientific Report, Vientiane, Laos 85, 2011.

[5] J. Murthy, 'Text book of Watershed management in India', Wiley, 2000.

[6] S. Yıldırımer, M. Özalp, E. Yüksel, "SRTM ve topoğrafik harita verileri kullanılarak Artvin ilindeki yağış havzalarının fiziksel özelliklerinin belirlenmesi”, Doğal Afetler ve Çevre Dergisi, 2(2), 71-80, 2016.

[7] M. Kızılaslan, F. Sağın, E. Doğan, O. Sönmez, "Aşağı Sakarya Nehri akımlarının yapay sinir ağları ile tahmin edilmesi”, Sakarya Üniversitesi Fen Bilimleri Dergisi, 18(2), 99-103, 2014.

[8] T. Küçükerdem, M. Kilit, K. Saplığlu, ' Bulanık çıkarım sistemlerinde kullanılan küme sayılarının kortalamalar ile belirlenmesi ve baraj hacmi modellenmesi: Kestel Barajı örneği'”, Pamukkale Üniversitesi Mühendislik Bilimleri Dergisi, 25(8), 962-967, 2019.

[9] Ö. Terzi, O. Özcanoğlu, "Gen ifade programlama ile Göksu Nehri'nin akım tahmini”, Mühendislik Bilimleri ve Tasartm Dergisi, 5(3), 483-487, 2017.

[10] A. Kökçam, E. Doğan, C. Erden, "Meriç Nehri akımlarının yapay sinir ağları ile tahmini', International Symposium on Natural Hazards and Disasters Management, 1-7, 2018.

[11] H. Demirpençe, “Köprüçay akımlarının yapay sinir ağları ile tahmini”, Antalya Yöresinin İnşaat Mühendisleri Sorunları Kongresi, 2015, Antalya.

[12] U. Okkan, A. Mollamahmutoğlu, "Yiğitler çayı günlük akımlarının yapay sinir ağları ve regresyon analizi ile modellenmesi", DPÜ Fen Bilimleri Enstitüsü Dergisi, Kütahya, 23(1), 33-48, 2010.

[13] Ö. Terzi, E. Keskin, "Yapay Sinir ağları yaklaşımı kullanılarak günlük hava buharlaşması tahmini", IMO Teknik Dergi, 3683-3693, 2005.

[14] E. Gemici, M. Ardıçlıŏlu, F. Kocabaş, "Akarsularda debinin yapay zekâ yöntemleri ile modellenmesi’, Erciyes Üniversitesi Fen Bilimleri Enstitüsü Dergisi, 29(2), 135-143, 2013.

[15] A. Yurdusev, M. Firat, "Adaptive neuro fuzzy inference system approach for municipal water consumption modeling: An application to izmir, Turkey", Journal of Hydrology, 365(1), 225-234, 2009.

[16] V. Gümüş, G. Soydan, O. Şimşek, 'Yağış-Akış ilişkisinin belirlenmesinde farklı yapay sinir ağı yöntemlerinin karşılaştırılması", Çukurova Üniversitesi Mühendislik Mimarlık Fakültesi Dergisi, 28(1), 37-49, 2013.

[17] U. Okkan, Y. Dalkılıç, "Radyal tabanlı yapay sinir ağları ile Kemer barajı aylık akımlarının modellenmesi”, IMO Teknik Dergi, 5957-5966, 2012. 
[18] J. Brasington, S. Richards, "Reduced-complexity, physically-based geomorphological modelling for catchment and river management", Geomorphology, 90(4), 2007.

[19] M, Strager et al., "A spatially explicit framework for quantifying downstream hydrologic conditions", Journal of Environmental Management, 90(5), 2009.

[20] P. Şahin, Y. İbrahim, A. Halit, ' Göksu nehri havzasının akış-yağış ilişkileri', Bartın Orman Fakültesi Dergisi, 21(3), 2019.

[21] C. Kara, A. Güngör, ' Distribution of fish fauna in Adıyaman region', Yunus Araştırma Bülteni, Adiyaman, 16(3), 2016.

[22] M. Bakırcı, " Türkiye'nin uluslararası ulaşımında demiryolu sınır kapılarının yeri ve etkinliği ', Marmara Coğrafya Dergisi, 28(1), 2013.

[23] Kahramanmaraş Meteoroloji İstasyon Müdürlüğü, Meteoroloji Ölçüm Raporları, Kahramanmaraş, 1995.

[24] A. Tribe, "Automated recognition of valley lines and drainage networks from grid digital elevation models: a review and a new method", Journal of Hydrology, 139(1), 1992.

[25] A. Şeker, B. Diri, H. Balık, ' 'Derin öğrenme yöntemleri ve uygulamaları hakkında bir inceleme', Gazi Mühendislik Bilimleri Dergisi, 3(1), 47-64, 2017.

\section{Özgeçmiş}

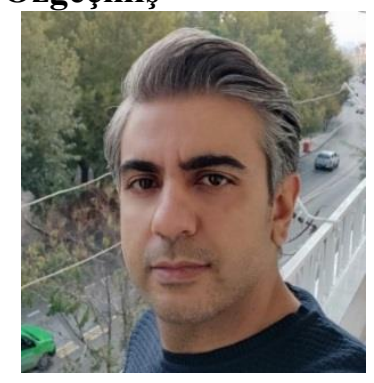

\section{Hüseyin Çağan KILINÇ}

Yazar 1986 yılında doğmuştur. Lisans ve yüksek lisans eğitimini Gaziantep Üniversitesi Mühendislik Fakültesi İnşaat Mühendisliğinde, doktorasını ise Hasan Kalyoncu Üniversitesi, Fen Bilimleri Enstitüsü, İnşaat Mühendisliği Anabilim dalında tamamlamıştır. Yazar İstanbul Esenyurt Üniversitesi, İnşaat Mühendisliği bölümünde öğretim üyesi olarak çalışmaktadır. İlgi alanına giren konular yapay zekâ, derin öğrenme, su temini ve ulaştırma alanına giren araştırma konularıdır.

\section{Beyanlar:}

E-Posta: huseyincagankilinc@esenyurt.edu.tr

Bu makalede bilimsel araştırma ve yayın etiğine uyulmuştur. 